\title{
Failure Analysis of Reverse Shaft in the Transmission System of All-Terrain Vehicles
}

\author{
Chun-Yuan Lin $\cdot$ Jui-Pin Hung $\cdot$ Tze-Chi Hsu
}

Submitted: 10 September 2007/in revised form: 3 December 2007/Published online: 12 January 2008

(c) ASM International 2008

\begin{abstract}
This paper presents a failure analysis of a reverse shaft in the transmission system of an all-terrain vehicle (ATV). The reverse shaft with splines fractured into two pieces during operation. Visual examination of the fractured surface clearly showed cracks initiated from the roots of spline teeth. To find out the cause of fracture of the shaft, a finite element analysis was carried out to predict the stress state of the shaft under steady loading and shock loading, respectively. The steady loading was produced under normal operation, while the shock loading could be generated by an abrupt change of operation such as start-up or sudden braking during working. Results of stress analysis reveal that the highest stressed area coincided with the fractured regions of the failed shaft. The maximum stress predicted under shock loading exceeded the yield strength and was believed to be the stimulant for crack initiation and propagation at this weak region. The failure analysis thus showed that the premature fatigue fracture of the shaft was caused by abnormal operation. Finally, some suggestions to enhance service durability of the transmission system of ATV are discussed.
\end{abstract}

\section{C.-Y. Lin}

Department of Mechanical Engineering, Nanya Institute of Technology, 414, Sec. 3, Jung-Shan E. Rd., Chungli 320,

Taiwan, P.R. China

J.-P. Hung $(\bowtie)$

Department of Automation Engineering, National Chin-Yi

University of Technology, 35, Lane.215, Sec. 1,

Chung-Shan Rd., Taiping 411, Taiwan, P.R. China

e-mail: hungjp@ncut.edu.tw

T.-C. Hsu

Department of Mechanical Engineering, Yuan-Ze University, 135 Yuan-Tung Rd., Chungli, Taoyuan, Taiwan, P.R. China
Keywords Fatigue failure - Spline shaft . All-terrain vehicles

\section{Introduction}

All-terrain vehicles (ATVs) can be considered fourwheeled motorcycles for off-road operation with both forward and backward movement but with the chain-driven mechanism designed for motorcycles substituted with a gear-driven mechanism. Such a gear-driven transmission system provides various speed-power ratios, enhancing the movements and power transmission efficiency. However, for a general-purpose gear box, the rotating shaft usually endures loadings associated with torsion and bending moments, producing a steady torsion stress and cyclic bending stress. As a result, the shafts are susceptible to fatigue failure during the operation [1].

In this study, the reverse shaft was used for backward movement of the ATV. The shaft assembly consists of a pinion gear and a multijawed coupling that are secured to the shaft with multispline teeth, rather than a single key. This assembly provides the capability for power transmission. With a straight-sided profile, the root of the spline tooth also becomes a stress raiser where fatigue cracks may initiate under fluctuating loadings [2], hence causing a premature fracture of shaft. Figure 1 shows a failed reverse shaft used in an ATV. This shaft fractured into two pieces near the section secured with a pinion gear.

An analytical approach based on mechanics of materials and failure criteria was adopted to determine the geometry of the shaft required to provide sufficient load-carrying capacity. However, unexpected fatigue fracture can still occur during operation and service [3-5]. To identify the cause of fracture of the shaft, this study investigated the 

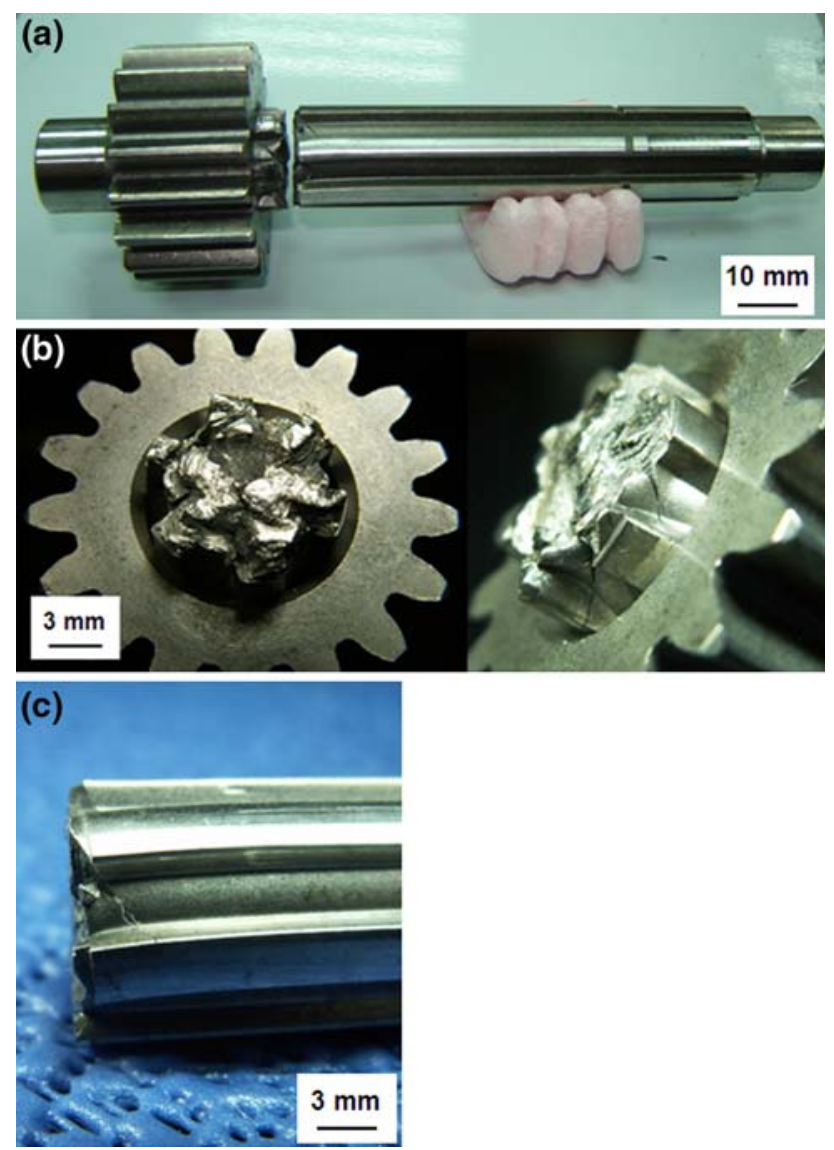

Fig. 1 Macrograph of the fractured shaft. (a) Failed shaft. (b) Close view of the fracture surface with cracks propagating at direction of $45^{\circ}$, approximately, to the shaft axis. (c) Permanently twisted deformation of spline teeth with cracks at root

stress conditions at the fractured regions by the finite element method. The fatigue failure analysis also provided a basis for some suggestions to raise the durability of the transmission system of the ATV.

\section{Visual Examination}

As shown in Fig. 1, the shaft fractured at the location secured with a pinion gear, where a maximum bending moment was produced by the transmitted force. The fracture surface was vertical to the axial direction of the shaft. The spline teeth near the fractured section were permanently twisted by the torsional forces. Detailed observations showed that cracks originated at the roots of splines. Fractures from spline roots have also been observed in a rear axle shaft [6] and a steering shaft of a similar vehicle [7]. This suggests that the spline tooth root is a preferential site to initiate failure. These "tooth root" cracks propagated toward the central zone in a direction making an angle about $45^{\circ}$ to the shaft axis. As a characteristic of fatigue fracture [8], the fractured surface roughly displays two distinct appearances. Most of fractured surface shows a bright appearance with shear lips. This indicates a plastic shear occurred during the propagation of the crack and suggests that the fracture occurred in a ductile manner. The remainder of the fractured surface displays a dark appearance caused by a sudden fracture after the initial crack growth. Obviously, the spline tooth with sharp corner at root might weaken the shaft; however, the working condition leading to the fracture should be further identified through the mechanical analysis.

\section{Stress Analysis}

\section{Shaft Loading}

Figure 2 shows the arrangements of the reverse shaft in the transmission gearbox, where the spline teeth on the shaft secured the driven pinion gear and jawed coupling. Both ends of the shaft were supported by ball bearings. During working, the spline shaft would simultaneously experience torque and bending moments. The bending moment was derived from transmitted force acting on the tooth surface of the pinion gear; the transmitted force herein is regarded

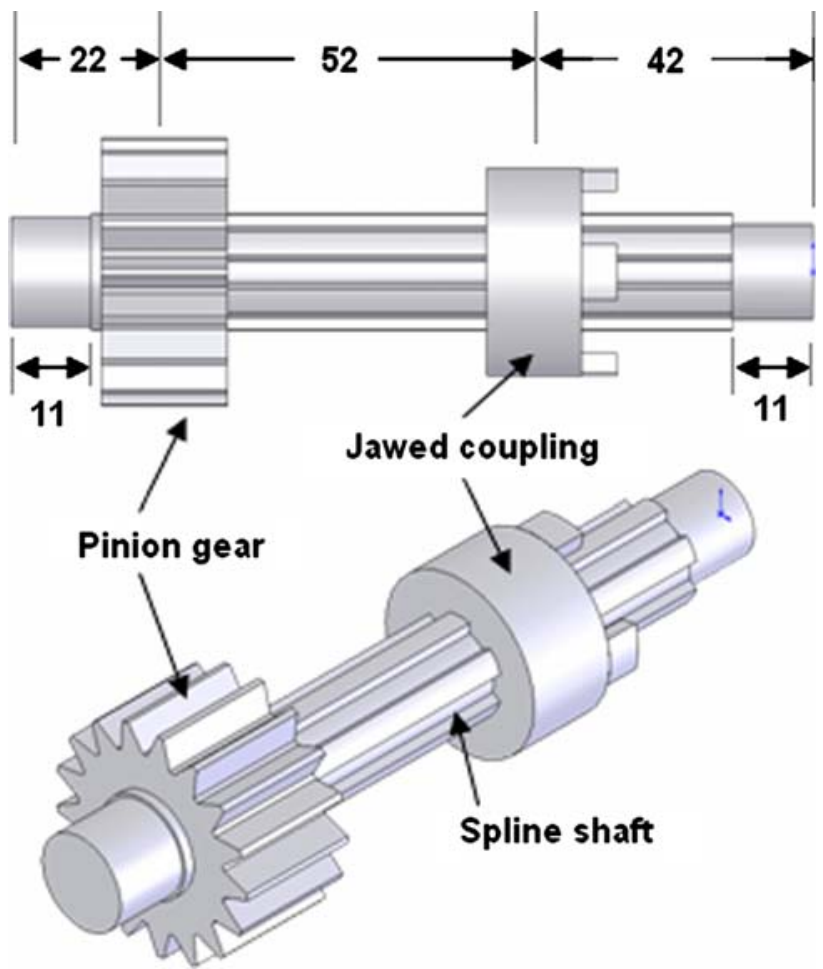

Fig. 2 Technical drawing of the reverse shaft, on which a pinion gear and jawed coupling are secured with multiple splines. The shaft has an outer diameter of $15 \mathrm{~mm}$ and root diameter of $12 \mathrm{~mm}$ at spline tooth 
as a lateral force imposed on the shaft axis. The torsion moment $T$ and transmitted force $F$ were calculated from the driven power $P(\mathrm{~kW})$ and rotational speed $N(\mathrm{rpm})$ of the shaft using:

$$
\begin{aligned}
& T=\frac{60 P}{2 \pi N} \\
& F=\frac{2 T}{D_{\mathrm{p}} \cos \alpha}
\end{aligned}
$$

where $D_{\mathrm{p}} \quad(=30 \mathrm{~mm})$ and $\alpha\left(=14.5^{\circ}\right)$ represent the pitch diameter and pressure angle of the pinion gear, respectively.

In this case, the engine power delivered to the reverse shaft is rated $12 \mathrm{~kW}$ at rotating speed of $5670 \mathrm{rpm}$. The loads exerted on the shaft as obtained using Eq. 1 and 2 were: torsion moment $T=20.21 \mathrm{~N} \cdot \mathrm{m}$ and transmitting force $F=1392 \mathrm{~N}$, and a maximum bending moment $(M=19.36 \mathrm{~N} \cdot \mathrm{m})$ was found to occur at the location of pinion gear.

Prior to the finite element analysis described in next section, the well-accepted analytical analysis was used to predict the stress level of the transmitting shaft. For a shaft subjected to combined steady loadings of torsion and bending moment, the maximum values of the static stresses at the spline root were calculated to be $140 \mathrm{MPa}$ tensile stress and $83 \mathrm{MPa}$ shear stress. In addition, if considering the shock loadings generated under an abrupt change of the operation such as start-up, or sudden braking, the dynamic effect was evaluated in terms of the load dynamic factors, $C_{\mathrm{m}}$ for bending moment and $C_{\mathrm{t}}$ for torsion moment, which were introduced in stress calculation [9]:

$$
\begin{aligned}
\sigma_{\max } & ==\frac{16}{\pi d^{3}}\left[C_{\mathrm{m}} M+\sqrt{\left(C_{\mathrm{m}} M\right)^{2}+\left(C_{\mathrm{t}} T\right)^{2}}\right] \\
\tau_{\max } & ==\frac{16}{\pi d^{3}} \sqrt{\left(C_{\mathrm{m}} M\right)^{2}+\left(C_{\mathrm{t}} T\right)^{2}}
\end{aligned}
$$

With a heavy-duty load factor (2.0 for bending and torsional moment), the maximum values of dynamic stress estimated at root diameter of spline tooth are $279 \mathrm{MPa}$ in tension and $165 \mathrm{MPa}$ in shear, respectively.

\section{Finite Element Modeling}

A finite element stress analysis was carried out to determine the stress concentration level at the fractured region of the shaft. Shown in Fig. 3 is the finite element model of the spline shaft created with hexahedral elements. This model consists of 16,096 elements and 18,753 nodes. Boundary conditions were applied at the bearing supported ends. The shaft loadings were applied on the finite element model: a twisting torque was simulated by applying

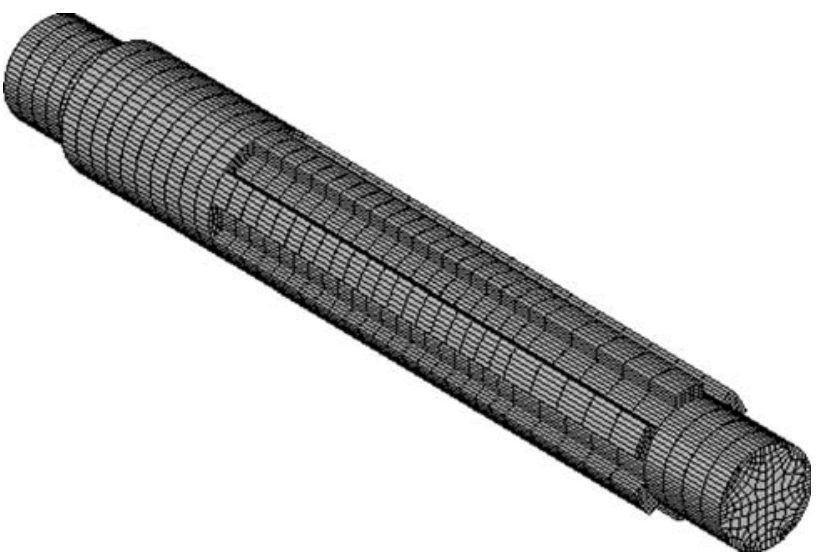

Fig. 3 Finite element model of a spline shaft, consisting of 16,096 brick elements and 18,753 nodes

tangential forces on the spline teeth secured with jawed coupling, and a bending moment was modeled by applying a distributive force normal to the outer surface of shaft secured with the pinion gear. The shaft was manufactured from medium carbon steel grade SAE/AISI 1045 with elastic modulus of $200 \mathrm{GPa}$, density of $7800 \mathrm{~kg} / \mathrm{m}^{3}$, and Poisson's ratio of 0.3 . Typical mechanical properties are given approximately as $585 \mathrm{MPa}$ for yield strength, $655 \mathrm{MPa}$ for ultimate strength, and $328 \mathrm{MPa}$ for fatigue strength $[10,11]$.

To understand the stress state of the shaft under various operations conditions, two different loading modes, static loading and dynamic loading, were assumed in stress analysis. The static loading modes assumed the reverse shaft being operated under normal rotating speed, and hence the driven torque and the bending effect were kept at steady state during operation. However, this is not always the case; the reverse shaft may experience shock force coming from abrupt change of the operating condition. The shock forces acting on the pinion gear and the spline teeth were termed impulsive loads because of their short duration. The response of the shaft to the impulsive loads can be characterized as a stress wave being generated at the loading instant and then propagating within the shaft. Under the shock loadings, the stress state was expected to be higher than that induced under normal operation. This could be realized through the transient analysis by implementing the implicit direct integration methods into finite element analysis.

\section{Results of Stress Analysis}

Figure 4 shows the distribution of the von Mises stress of the shaft subject to a steady transmitted load under normal operation. As seen from this figure, the highest stresses occur at the regions secured with pinion gear where the 


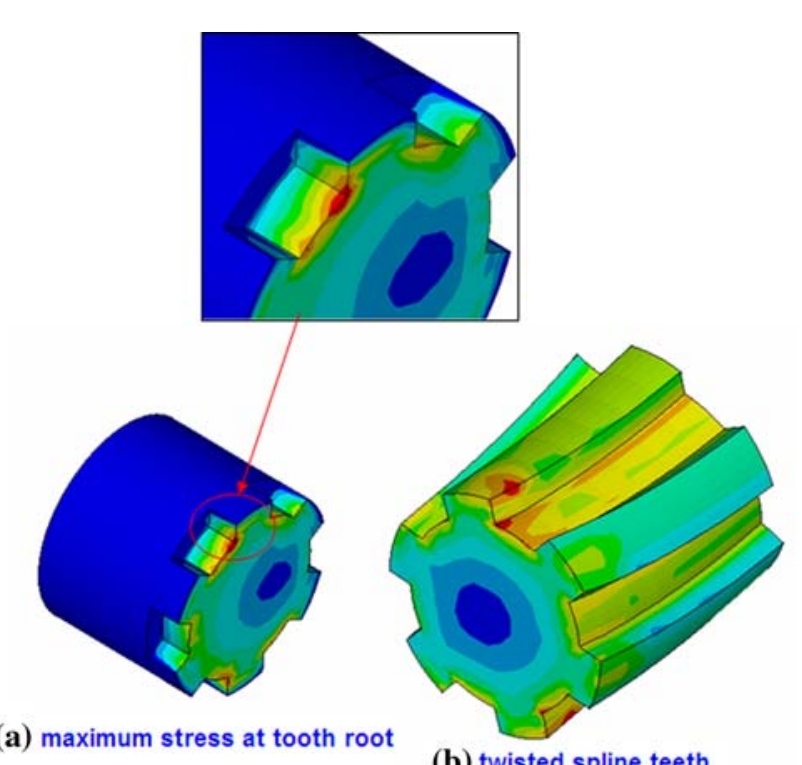

$\begin{array}{ll}\text { (a) maximum stress at tooth root } & \text { (b) twisted spline teeth }\end{array}$

$$
._{.687611}{ }_{25.734^{50.781}}{ }^{75.827}{ }^{100.874}{ }_{125.921}^{150.967}{ }_{176.014^{201.061}} 226.107
$$

Fig. 4 Distribution of the von Mises stress of the shaft near the region secured with the pinion gear, where fracture occurred in a failed shaft (stress unit: MPa). (a) Maximum von Mises stress located at the root of spline tooth. (b) Twisted deformation of the spline teeth. Magnification: $200 \times$

maximum bending moment is produced. It is noted that the location of the stress peak agrees with the fractured region as revealed by examination of the failed shaft. The maximum tensile stress and shear stress at this region are 276 and $110 \mathrm{MPa}$, respectively. The stress levels, however, are significantly below the yield strength of the shaft material.

The results obtained from transient analysis are presented in the Fig. 5, showing the time history of the maximum tensile stress of the shaft responding to the shock loading. It is found that the largest tensile stress (534 MPa)

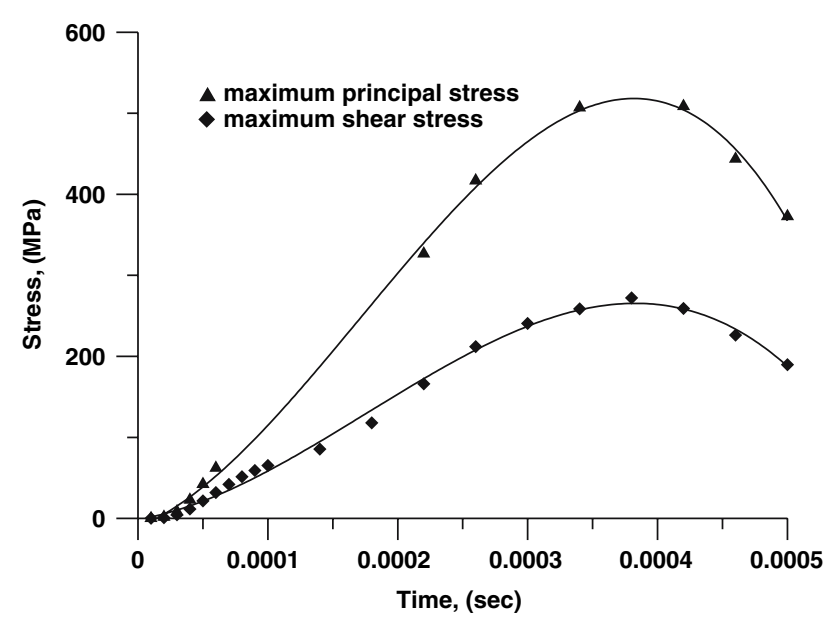

Fig. 5 Time history of the maximum stress responding to the shock loading on the shaft and shear stress $(272 \mathrm{MPa})$ are reached at the time of $0.38 \mathrm{~ms}$ after the shock loading initiated. Also, this maximum tensile stress is predicted to occur at the fractured section and is approximately 1.93 times the stress predicted under steady loading modes. In addition, the analytical solution reported a lower level of dynamic stress than that obtained from steady-state operation. This can be ascribed to the inertia effects that accompanied the propagation of stress wave within the shaft. Such impact effects are usually evaluated by employing a dynamic load factor in stress calculation to modify the influence of shock loading. This reveals that the analytical analysis in conventional shaft design practice may not be conservative. Furthermore, comparison of the induced stress and strength of shaft reveals that the shock loading, rather than the normal loading, might be the stimulant for crack initiation and propagation at the weak regions.

\section{Failure Analysis}

A failure analysis to identify the main cause of the fracture of the reverse shaft based on the results of finite element stress analysis is described. First, according to the static failure criteria [9], the reverse shaft under normal operation with steady speed has a minimum safety factor of 1.74. This implies that the normal load of steady mode would not bring the shaft to yield or fracture. In addition, due to the rotational shaft loading, the working stresses generated at the roots of spline teeth actually fluctuate from $276 \mathrm{MPa}$ in tension to $-276 \mathrm{MPa}$ in compression during one revolution of shaft. Such an alternating stress can be considered a fully reversed stress with amplitude of $276 \mathrm{MPa}$. This stress amplitude is lower than the fatigue strength (330 MPa) of the shaft material. This reveals that the reverse shaft running at normal speed would not contribute to the fatigue fracture. However, the shaft obviously failed but should have been fine according to the static failure analysis. Therefore, the shaft capacity designed under the normal loading conditions could not ensure a long-term safe operation.

As was shown in stress analysis, a higher tensile stress (534 $\mathrm{MPa}$ ) was predicted for shaft subject to transitional loadings. This stress significantly exceeds the yield strength of the shaft material and may thus produce localized plastic strains and accelerate fatigue. Although no immediate fracturing was expected to occur, accumulations of the plastic strains might cause fatigue cracks to initiate and propagate at these stress concentration sites. Figure 1 clearly demonstrates the evidence of crack propagation in the fractured sections. On the other hand, from the transient response to the shock loadings, the maximum tensile stress at the critical point behaves in a nonreversed cyclic 
characteristic. For a mechanical component experiencing a repeatedly fluctuating stress, the occurrence of fatigue fracture can be predicted according to the Basquin's power law [12], which was developed based on the stress-life test data. This power law is given by:

$A=\sigma_{\mathrm{R}} N_{\mathrm{R}}^{\mathrm{B}}$

where $\sigma_{\mathrm{R}}$ is the cyclic stress, $N_{\mathrm{R}}$ is the lifetime of fatigue failure, and the constants $A$ and $B$ are related to the material strengths and can be determined from:

$A=\frac{\left(0.9 \sigma_{\mathrm{ut}}\right)^{2}}{\sigma_{\mathrm{e}}}, \quad B=\frac{1}{3} \log \left(\frac{0.9 \sigma_{\mathrm{ut}}}{\sigma_{\mathrm{e}}}\right)$

where $\sigma_{\mathrm{e}}$ and $\sigma_{\mathrm{ut}}$ are the fatigue strength and ultimate strength of material, respectively.

In addition, for a nonreversed cyclic stress, the mean stress effect on fatigue failure should be taken into consideration in life prediction. The working stress with stress amplitude $\sigma_{\mathrm{r}}$ and mean stress $\sigma_{\mathrm{m}}$ were converted to an equivalent fully reversed stress by using the Goodman failure criteria [13], that is:

$\sigma_{\mathrm{R}}=\frac{\sigma_{\mathrm{r}} \sigma_{\mathrm{ut}}}{\sigma_{\mathrm{ut}}-\sigma_{\mathrm{m}}}$

Results of transient analysis show that the principal stress induced at the stress concentration regions varies from minimum value $\sigma_{\min }(0)$ to maximum value $\sigma_{\max }$ (534 MPa) at each loading instant. From Eq. 7, the equivalent fully reversed stress was then estimated to be $450 \mathrm{MPa}$, which exceeded the fatigue strength (328 MPa). The finite lifetime was then calculated as $N_{\mathrm{R}}=24,313$ loading cycles. With a lifetime less than 1 million loading cycles, the premature failure of reverse shaft can be identified as a fatigue fracture caused by the shock or transient loadings, rather than the steady loadings.

The fatigue fracture was characterized by the initiation of microcracks at highly stressed points and then followed by the propagation of the cracks from surface into the central zone with the fluctuating loading cycles. Therefore, it can be inferred from results of stress analysis that the shock loadings were the main force driving the cracks to propagate toward the core of the shaft, which hence gradually reduced the load-carrying capability of the shaft and led to sudden fracture in service. As a consequence of the shock loading, the spline teeth near the fractured surface were permanently deformed by the transient (impact) stresses that exceeded the yield strength. As shown in Fig. 1, photographic evidence of the cracks development on the tooth root clearly suggests fatigue fracture of a failed shaft. Conclusions from failure analysis show that the design of the reverse shaft established under normal operation condition was not sufficient to guarantee the long-term service and that the shock or transient loadings are an important factor in the durability of the transmission system of ATV.

\section{Design Implications}

The geometric specifications of the reverse shaft were insufficient to support transient loading of the shaft material. The results of failure analysis show that the fatigue behavior is dominated by the operating conditions in service and that these conditions are primarily the transient loads. The equivalent fully reversed stresses that result from the transient loads can be considered the minimum fatigue strength required for shaft to work safely with a desired service life.

The reverse shaft in this study was sized by ATV manufacturer without transient load input. Therefore, to prevent fatigue damage and increase the service life of the driven shaft, material strengths are critical. In practice, manufacturing processes and metallurgical techniques are known to have a significant effect on fatigue properties of mechanical parts [14]. In the case of carbon steel with hardened surface, the ultimate tensile strength (UTS) has been shown to be experimentally related to the Brinell hardness number $(\mathrm{BHN})$ by the form of UTS $(\mathrm{MPa})=$ $3.4 \times \mathrm{BHN}$ [9]. Also, fatigue properties are frequently correlated with tensile properties. Using the carbon steel as an example, the fatigue limit is approximately $50 \%$ of the ultimate tensile strength [9]. It therefore seems feasible to improve the fatigue strength through a heat treatment of the spline shaft. Treatments such as case hardening followed by quenching and tempering may be possible, but quench cracks must be eliminated.

Apart from the standard medium carbon steel, alloyed steels with higher strength are candidates for manufacturing of shaft. Some typical alloyed steels with different strengths are presented in Table 1, in which the equivalent fully reversed stresses for each material are estimated according to Eq. 7. Among the materials listed in Table 1, the alloyed steel grade AISI 5140 can be recommended for shafts since it has adequate strength to prevent fatigue damage.

On the other hand, the fractured shaft illustrated the indication of cracking within the highly stressed regions of the materials. According to the fracture mechanics, for a mechanical component with small cracks initiated at a highly stressed area, the fracture toughness became a prevalent factor. As they are different from the stress fields directly used in strength life method for fatigue analysis, the stress intensity factors are employed to describe the stress fields around crack sites [15]. Consequently, to clarify the actual fracture scenario in reverse shaft, a fracture mechanics based analysis could be a competent 
Table 1 Mechanical strength of alloyed steels [11] all data are cited from web sites: http://www.efunda.com/materials

\begin{tabular}{|c|c|c|c|c|c|c|}
\hline AISI code & $\begin{array}{l}\text { Tensile } \\
\text { strength, MPa }\end{array}$ & $\begin{array}{l}\text { Yield } \\
\text { strength, MPa }\end{array}$ & $\begin{array}{l}\text { Fatigue } \\
\text { strength }^{\mathrm{a}}, \mathrm{MPa}\end{array}$ & $\begin{array}{l}\text { Equivalent fully } \\
\text { reversed stress, MPa }\end{array}$ & Impact energy, $\mathrm{J}$ & Heat treatment condition \\
\hline 1045 & 655 & 585 & 328 & 450 & $\cdots$ & Standard, cold drawn. $\mathrm{BHN}=179$ \\
\hline 1050 & 748 & 428 & 374 & 415 & 27.1 & $\begin{array}{l}\text { Normalized: heated to } 900{ }^{\circ} \mathrm{C} \text {, } \\
\text { air cooled. } \mathrm{BHN}=217\end{array}$ \\
\hline 4130 & 669 & 436 & 335 & 444 & 86.4 & $\begin{array}{l}\text { Normalized: heated to } 870{ }^{\circ} \mathrm{C} \text {, } \\
\text { air cooled. } \mathrm{BHN}=197\end{array}$ \\
\hline 5140 & 793 & 472 & 397 & 402 & 38.0 & $\begin{array}{l}\text { Normalized: heated to } 870{ }^{\circ} \mathrm{C} \text {, } \\
\text { air cooled. } \mathrm{BHN}=229\end{array}$ \\
\hline
\end{tabular}

${ }^{\text {a }}$ Fatigue strengths are approximated as $50 \%$ of the ultimate tensile strength [9]

approach to design. The fatigue life can be estimated from strain-life method for crack initiation stage and the Paris law for crack growth stage, respectively [15]. Based on this consideration, the ductility-related cyclic properties such as fatigue strength coefficient, ductility coefficient, fracture toughness, and so forth, are more important than static strength, and hence a shaft with enough fracture toughness will be regarded as an essential requirement for preventing the fracture of the shaft in service.

Fracture toughness represents the ability of a material to resist the development of the cracks, and although increasing surface hardness can properly improve static tensile strength and fatigue strength, it will lower the fracture toughness of material and accelerate final fracture. From Table 1, it can be found that the Brinell hardness is positively correlated to the material strength, but has a slightly negative correlation with the impact strength. Since the fracture toughness of heat treated material is often unavailable, the impact energy is used to describe the ability to resist fracture. Generally, the impact properties are not employed directly in fatigue fracture analysis, but the more economical impact tests have been used as a quality-control method to assess toughness and compare the relative toughness of engineering materials. As listed in Table 1, the material grade AISI 4130 shows a higher toughness although it has lower fatigue strength. This suggests that material grade AISI 4130 may also be an alternative for manufacturing the shaft.

\section{Conclusions}

A fractured spline shaft has been analyzed by finite element analysis and fatigue failure considerations. Some conclusions are summarized:

- The root of the spline teeth secured with the transmitted gear is the weakest regions, where a maximum stress with nonreversed cyclic characteristic is generated under transmitted loadings.
- The shock or transitional loads produced by an abrupt change of operation are the main stimulant for crack initiation and propagation at the spline tooth root.

- To design a transmitted shaft with high service durability, mechanical characteristics such as fatigue strength, ultimate tensile strength, and fracture toughness are important properties that should be considered in material selection at design stage.

\section{References}

1. Wulpi, D.: Failures of shafts. In: Failure Analysis and Prevention, vol. 11, 9th edn., Metals Handbook, pp. 459-482. American Society for Metals, Metals Park, OH (1986).

2. Rice, R.C. (ed.): Fatigue Design Handbook-AE-10, Society of Automotive Engineers, Warrendale, PA (1988).

3. Xu, I.L., Yu, Z.W., Ding, H.X.: Failure analysis of a diesel engine gear-shaft. Eng. Fail. Anal. 13, 1351-1357 (2006).

4. Bhaumik, S.K., Rangaraju, R., Parameswara, M.A., Venkataswamy, M.A., Bhaskaran, T.A., Krishnan, R.V.: Fatigue failure of a hollow power transmission shaft. Eng. Fail. Anal. 9, 457-467 (2002).

5. Li, Y.J., Zhang, W.F., Tao, C.H.: Fracture analysis of a castellated shaft. Eng. Fail. Anal. 14, 573-578 (2007).

6. Nanawarea, G.K., Pableb, M.J.: Failures of rear axle shafts of 575 DI tractors. Eng. Fail. Anal. 10, 719-724 (2003).

7. Cleland, J.H.: Shear failure of a road-vehicle steering shaft. Eng. Fail. Anal. 4(1), 81-88 (1997).

8. Bonnett, A.H.: Root cause ac motor failure analysis with a focus on shaft failures. IEEE Trans Industry Application. 36(5), 11971209 (2000).

9. Shigley, J.E.: Mechanical Engineering Design. Matrix edn. McGraw-Hill Book Co., New York (1986).

10. Dimarogonas, D.: Machine Design-A CAD Approach. John Wiley \& Sons (2001).

11. Web site: http://www.efunda.com/materials.

12. Basquin, O.H.: The exponential law of endurance tests. Am. Soc. Test Mater. Proc. 625-630 (1910).

13. Hertzberg, R.W.: Deformation and fracture mechanics of engineering materials. John Wiley \& Sons, New York, 530-532 (1996).

14. Matlock, D.K., Alogab, K.A., Richards, M.D., Speer, J.G.: Surface processing to improve the fatigue resistance of advanced bar steels for automotive applications. Mater. Res. 8(4), 453-459 (2005).

15. Dieter, G.E.: Mechanical Metallurgy. SI Matrix edn. McGraw Hill Book Co., New York (1988). 